\title{
Surface Modification of Titanium Plate with Anodic Oxidation and Its Application in Bone Growth*
}

\author{
Sahar A. Fadl-allah ${ }^{1,2}$, Mohsen Quahtany ${ }^{1}$, Nahla S. El-Shenawy ${ }^{3,4 \#}$ \\ ${ }^{1}$ Materials and Corrosion Lab (MCL), Faculty of Science, Taif University, Taif, KSA; ${ }^{2}$ Chemistry Department, Faculty of Science, \\ Cairo University, Giza, Egypt; ${ }^{3}$ Zoology Department, Faculty of Science, Taif University, Taif, KSA; ${ }^{4}$ Zoology Department, Faculty \\ of Science, Suez Canal University, Ismailia, Egypt. \\ Email: "elshenawy_nahla@hotmail.com
}

Received October $9^{\text {th }}, 2012$; revised November $15^{\text {th }}$, 2012; accepted December $16^{\text {th }}, 2012$

\begin{abstract}
Using implants for dental applications are well-accepted procedures as one of the solutions for periodontal defect repair. Suitable design and materials, their reaction with the surrounding hard tissues and interfacial biomechanical properties are still considered to be the primary criteria which need to be addressed. The purpose of present study was to evaluate the bone repair around pure titanium implants and porous surface using anodic oxidation technique, after their insertion in tibiae of rats $(n=15)$. Five animals received pure titanium-surface implants in tibia, 5 rough-surface implants $\left(\mathrm{TiO}_{2} / \mathrm{Ti}\right)$ in tibia and last five acted as control group. The interfacial integrity and compositional variation along the interface were studied using scanning electron microscope (SEM) with energy dispersive analysis of X-ray (EDX) and histopathology after 2 months. The rats were sacrificed 8 weeks after surgery and fragments of the tibiae containing the implants were submitted to histological analyses to evaluate new bone formation at the implant-bone interface as well as the tibiae were radio graphed. The SEM-EDX results confirmed the initial stability for the Ti implant, but the regeneration of new bone formation was faster in the case of $\mathrm{TiO}_{2} / \mathrm{Ti}$ implant, and hence could be used for faster healing. The results of the histological analysis showed that osseointegration occurred for both types of implants with similar quality of bone tissue. In conclusion, the porous-surface implants contributed to the osseointegration because they provide a larger contact area with surface roughness at implant-bone interface can help into the formation of physico-chemical bondage with the surrounding hard tissues.
\end{abstract}

Keywords: Anodic Oxidation Treatment; Electron Diffraction X-Ray; Titanium; Titanium Oxide; Histology; Radiograph

\section{Introduction}

Pure titanium and titanium alloys are the most used biomaterials for fabrication of surgical implants due to their excellent mechanical properties, biocompatibility [1] and resistance to corrosion [2]. They are considered ideal materials because they have shown better acceptability by human tissues than other metals under diverse circumstances [1]. The discovery of relatively inert metals and alloys has led to the increasingly widespread use of metal implants in orthopedics and dentistry. Pure titanium and titanium alloys are the most frequently used materials for osseointegrated dental and orthopedic implants because of their biocompatibility [3-5]. Biocompatibility is attributed to the formation of a protective layer of titanium dioxide $\left(\mathrm{TiO}_{2}\right)$ that avoids direct contact between the implant and its milieu [1]. This protective

\footnotetext{
${ }^{*}$ The author declares that there are no conflicts of interest.

\#Corresponding author.
}

layer reduces the reactivity of the metal. Ti without any surface treatment is bioinert, to further improve the bioactivity and biocompatibility of titanium; various types of surface modification method have been explored [6]. So that several efforts were directed to the modification of metal surfaces which are often employed as a mean of controlling tissue-titanium interactions and shortening the time of bone fixation [6,7].

The high biocompatibility of titanium derives partially from the stable and protective oxide layer, which apparently aids in connecting extracellular matrix to the implant surface [1]. The knowledge of the biomaterial-bone tissue interface is extremely important to define which material would promote a better tissue response and which kind of surface would be more adequate for the proliferation of bone cells [8]. After placement of an implant in the surgical cavity, several cellular events take place. Ideally, these events should lead to wound healing by intimate apposition of the bone to the biomaterial, i.e., 
osseointegration [9].

Regardless of their external shape of the implants, microscopically they can present smooth, porous or textured surfaces [10-15]. Several studies have shown that the success or failure of surgical implants can be related to chemical $[13,16]$ and biological properties [16] of their surfaces as well as to their micromorphology [17] The differences in the microstructure of implant surfaces seem to influence stress distribution, bone retention, cellular response on its surface and consequently the osseointegration [16,18-20].

Porous implants have been developed to be stabilized by bone ingrowth into the pore [13,15]. Oliveira et al. [19] determined that, although the fabrication process parameters have been optimized, the ideal porous requirements for surgical implants have not yet been reached. These authors reported that some changes are necessary in order to increase porosity and advocated that an analysis of pore size distribution along the sample has been performed to indicate more efficiently which porous fraction would better meet implant requirements [21]. Togni et al. [22] studied the histomorphometric analysis of bone tissue repair in rabbits after insertion of titanium screws under different torque. We report a successful creation of $\mathrm{TiO}_{2}$ nano-porous surfaces that mimic biomineralized matrices [23]. Therefore, the purpose of present study was to analyze, by histological methods, the bone repair over pure titanium implants with nano-porous $\mathrm{TiO}_{2}$ surface, after their insertion in tibiae of rats.

\section{Materials and Methods}

\subsection{Coating Preparation of Titanium Plate (Anodic Oxidation Treatment)}

Titanium foil (Sigma-Aldrich Chemie GmbH, Riedstr. 2D-89555 Steinheim 497329 970) with 0.25 mm thick, 99.7\% metals basis was used as base material in this study. The exposed metal surface (area: $1 \mathrm{~cm}^{2}$ ) of each specimen was ground with silicon carbide paper to 2000 grit, washed in distilled water and then rinsed with alcohol before implantation [23]. As a result of this mechanical polishing process, Ti plate samples were prepared to be implanted in rats. Anodic oxidation treatment was used to prepare $\mathrm{TiO}_{2}$ plate sample. The electrolyte used in this work contained $1 \mathrm{M} \mathrm{H}_{2} \mathrm{SO}_{4}+0.5 \mathrm{wt} \% \mathrm{NaF}$. Nano oxide coat from $\mathrm{TiO}_{2}$ was obtained using a twoelectrode system. Rectangular samples of titanium area 1 $\mathrm{cm}^{2}$ were used as the anode and a platinum plate of area $3 \times 3 \mathrm{~cm}^{2}$ was used as the cathode. The operations involved were in the following sequence: a) mechanical polishing; b) the metallic sheet was then cleaned ultrasonically in acetone; and c) anodizing at $20 \mathrm{~V}$ in the electrolytic bath for $20 \mathrm{~min}$ as a result of this process, $\mathrm{TiO}_{2}$ samples were prepared which appear as nano porous layer [23] and were used for implantation.

\subsection{Morphology Characterization and Chemical Composition of Examined Samples}

The surface morphology and chemical composition of the untreated and treated titanium samples, $\mathrm{Ti}, \mathrm{TiO}_{2} / \mathrm{Ti}$-plate, before and after implantation process were studied by scanning electron microscopy (SEM) with electron diffraction X-ray (EDX) system by JEOL-840 Electron prop micro analyzer.

\subsection{Animals}

Fifteen male, adult Sprague-Dawley rats were used in this study and were purchased from King Fahed Medical Research Centre in Jeddah (Kingdom of Saudi Arabia). The average weight of the animals at surgery was $224 \mathrm{~g}$; after 8 wk of osseointegration the average weight was 375 g. This weight gain is normal in healthy male rats. As described below, titanium implants were implanted in tibia of each animal. The un-operated tibia was used as histological control. For the entire experimental period two or three animals were kept in each cage with an unlimited supply of fresh water and rodent pellets. The European Community Directive (86/609/EEC) and National rules on animal care have been followed.

\subsection{Implants}

Experimental implants were manufactured from pure titanium. The implants had an overall length of $3 \mathrm{~mm}$. A $1.0 \mathrm{~mm}$ thickness; smooth middle section had a diameter of $1.0 \mathrm{~mm}$. The implants were cleaned using oscillating ultrasound equipment after placing them in n-butanol within a glass container. They were processed two times for 10 min each time, with a change of liquid. The objects were then rinsed three times and processed another $10 \mathrm{~min}$ in 70 percent ethanol. From this stage, in order not to contaminate the titanium surface, the implants were kept in a dry glass container. Finally, the implants, together with all necessary instrumentation, were moist-sterilized at $134^{\circ} \mathrm{C}$ for $40 \mathrm{~min}$.

\subsection{Anesthesia and Surgery Technique}

The animals were anesthetized intraperitoneally with a solution of $8 \mathrm{mg}$ ketamine chlorlhydrate and $1.28 \mathrm{mg}$ xylazine per $100 \mathrm{~g}$ body weight. The skin of right tibiae was shaved before a $1.5 \mathrm{~cm}$ incision was made along the tibial crest. The region of surgery surface was cleaned with antiseptic. The subcutaneous tissue, muscles and ligaments were dissected to expose the lateral external surface of the diaphyseal bone. An end-cutting bur was used to drill make a crack $1.5 \mathrm{~mm}$ in diameter with manual rotating movements to avoid overheating and necrosis of 
the bone tissue [24]. Plates of uncoated and coated Ti of $3.0 \times 1.0 \times 1.0 \mathrm{~mm}$ were implanted in tibia of rats.

\subsection{Tissue Collection and Histological Examination}

In vivo biocompatibility of $\mathrm{TiO}_{2} / \mathrm{Ti}$ coating was determined by implanting in the plates in rat tibia. The animals were anesthetized with the same procedure used for implant surgery. The rats were sacrificed after eight weeks of healing and the bone specimens with uncoated $\mathrm{Ti}$ and coated Ti implants were retrieved. The Tibiae were removed and all specimens were X-rayed using dental equipment. A hydrated aluminum chloride solution (7 percent, w/v) with formic acid (5 percent, v/v), $\mathrm{HCl}(8.5$ percent, $\mathrm{v} / \mathrm{v}$ ), and distilled water was used to decalcify the bone specimens. The bone became sufficiently soft after 2 $3 \mathrm{~d}$ in this solution at $4^{\circ} \mathrm{C}$. Phosphate buffer rinse stopped the decalcification process. The specimens were fixed in $10 \%$ phosphate-buffered formalin ( $\mathrm{pH} 7.25$ ) for 10 days and dehydrated in graduated ethanol $(70 \%$ for $30 \mathrm{~min}$, $95 \%$ for $30 \mathrm{~min}$, and $100 \%$ for $2 \times 1 \mathrm{~h}$ ) series. After embedding samples in Spurr's resin, each undecalcified implant block was sectioned perpendicular to the implant surface using a low speed diamond saw [25]. After polishing, the sections were stained by heamatosaline and eosin stain and observed under light microscope (Olympus BH-2, Olympus America Inc., NY, USA) with a digital camera (DS-55M-L1; Nikon) [26].

\section{Results}

\subsection{Surface Analysis of Ti Samples before and after Anodization Process}

The results of SEM micrographs, Figures 1(a) and (b), of Ti samples before and after anodization, respectively show that: a) the surface appearance of the mechanically polished pure Ti sample (uncoated) represented the typical morphology of native oxide film, with thin and nonporous structure; b) the anodic oxide film, $\mathrm{TiO}_{2}$, showed that the surface of Ti specimen (coated) appear as the network forms with nano porous slots. The EDX spectrum of untreated and treated titanium spacemen's were presented in Figures 2(a) and (b), which indicated that the chemical composition of both samples oxide layer is $\mathrm{Ti}$ in addition to oxygen and small percentage from fluoride for only anodized Ti sample. The surface analysis results of untreated and anodized Ti samples confirmed that the major element present on the surface is Ti.

\subsection{Photograph and $X$-Rays Finding}

All implants had characteristic signs of bone ingrowth in various regions along their length. There were apparent differences in the amount or distribution of bone in

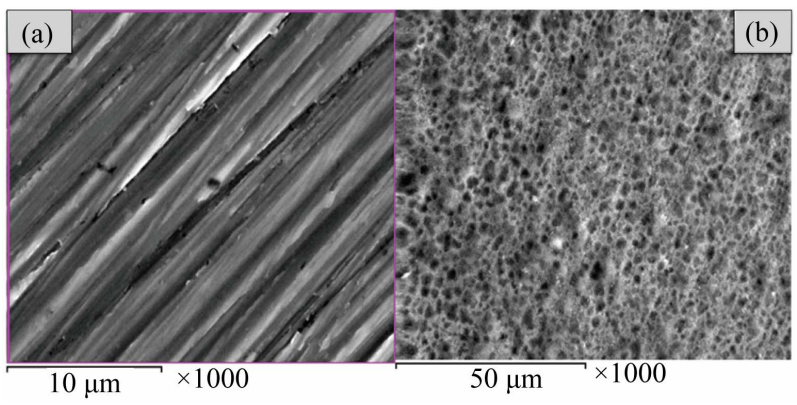

Figure 1. Scanning electron microscope (SEM) micrographs of the Ti specimens before and after electrochemical anodization treatment: (a) uncoated Ti specimen; (b) anodized coated Ti specimen.

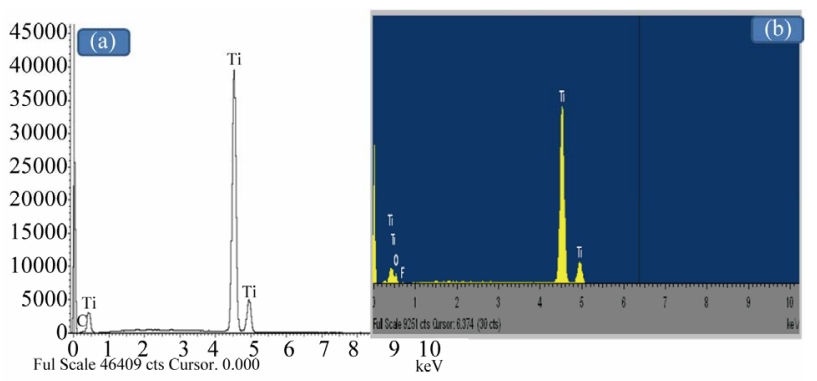

Figure 2. Energy dispersive X-ray analysis (EDX) micrographs of the Ti specimens before and after electrochemical anodization treatment: (a) uncoated Ti specimen; (b) anodized coated $\mathrm{Ti}$ specimen.

growth between the uncoated and coated Ti evaluations (Figures 3(a) and (b)). Densification of bone immediately adjacent to the porous fiber metal, suggestive of bone ingrowth and load transfer, was observed locally at coated $\mathrm{TiO}_{2} / \mathrm{Ti}$ (Figure 3(b)) while, the Ti plate was not cover completely after two months of implantation (Figure 3(a)). No visible cracking can be seen in the tibia bone after 8 wk of $\mathrm{TiO}_{2} / \mathrm{Ti}$-plate implantation. X-rays of tibia specimens taken at 8 wk (Figures 4(a)-(c)) showed that all implants were within the modularly cavity and all were intact as compared to control.

\subsection{Microstructure of Ti Samples after Implantation Process}

The results of SEM micrographs of different examined samples after implantation process (Figure 5) show that new bone formation was not similar in both groups, a good bone healing is appear on $\mathrm{TiO}_{2} / \mathrm{Ti}$ sample (coated implant). So there was new bone formation around the anodized coated implant leading to osseointegration (Figure 5(b)). In the case of Ti-implantation the new bone formation was noticed on the sides of plate only (Figure 5(a)). The results of EDX micrographs (Figure 6) of examined implanted samples show that: a) the presence of $\mathrm{Ca}, \mathrm{P}$ on Ti implant sample; b) The presence of $\mathrm{Ca}, \mathrm{P}$, 

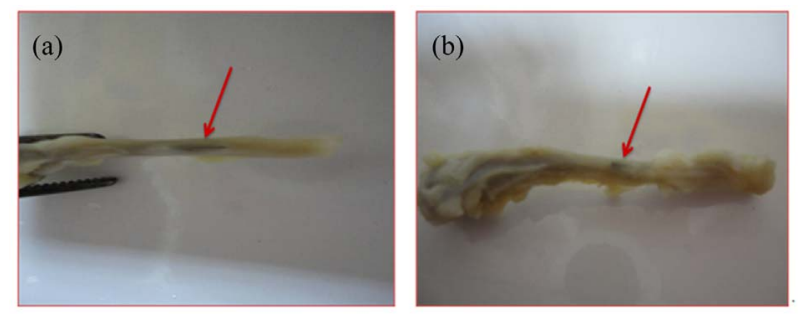

Figure 3. The photograph of the uncoated (a) and coated $\mathrm{TiO}_{2} / \mathrm{Ti}$ plates (b) after 8 wk of implantation. Red arrow points to the place of implantation.

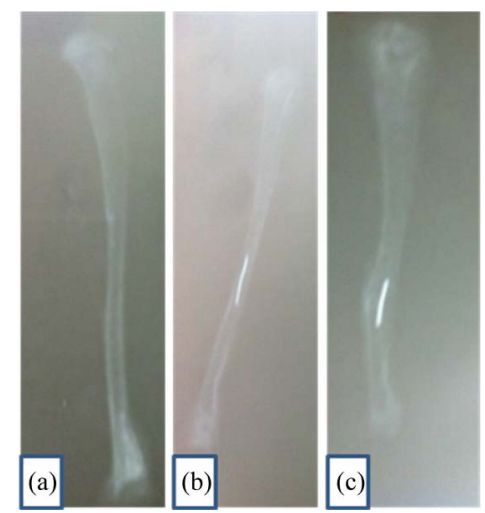

Figure 4. Radiograph for the bone: (a) control; (b) after implantation of $\mathrm{TiO}_{2} / \mathrm{Ti}$ and (c) after implantation of $\mathrm{Ti}$. The light line in the bone indicates to the plate of implantation.

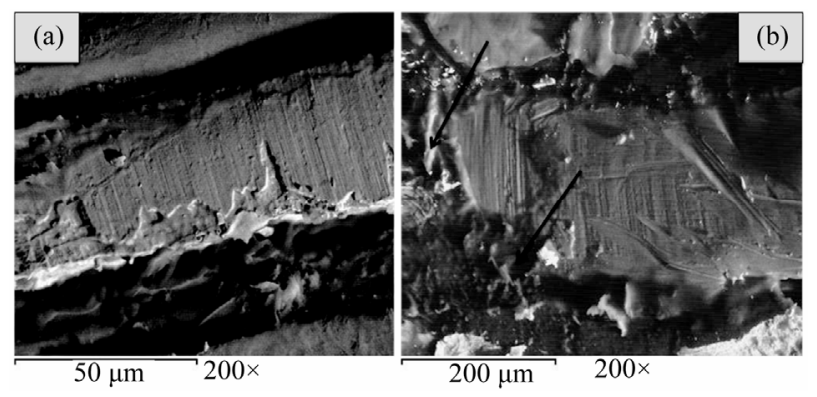

Figure 5. Scanning electron microscope (SEM) micrographs of the examined specimens after implantation process: (a) uncoated Ti specimen; (b) anodized coated Ti specimen.

and $\mathrm{O}$, the essential ingredients of bone cells on anodized titanium implant sample, $\mathrm{TiO}_{2} / \mathrm{Ti}$. It is clear that an array of $\mathrm{TiO}_{2}$ nano-porous structure well adherent on Ti implant surface can be useful for accelerated bone growth in orthopedic/dental applications. We noticed that the Ca peaks are detected in two implantation process this pointed to the bone healing occur either with $\mathrm{Ti}$ or $\mathrm{TiO}_{2} / \mathrm{Ti}$ but with a good proliferation with $\mathrm{TiO}_{2} / \mathrm{Ti}$ as the arrows indicate in Figure 6(b).

\subsection{Animals and Implants}

All animals presented satisfactory postoperative results, without any evidence of inflammation or infection of the

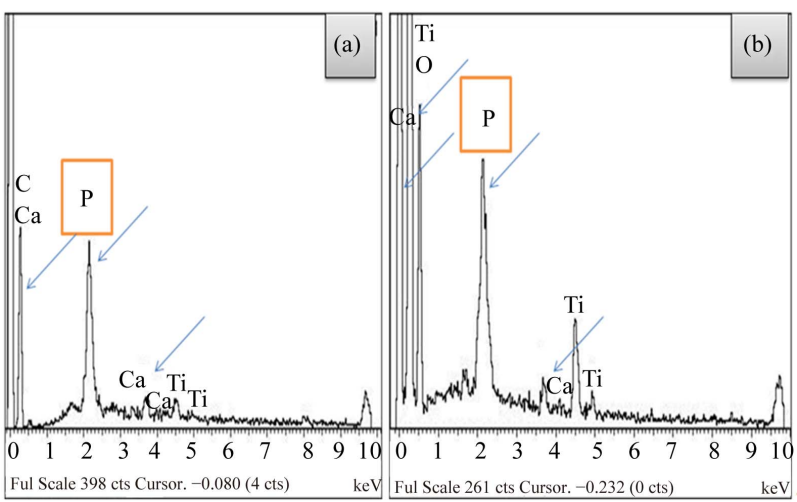

Figure 6. Energy dispersive X-ray analysis (EDX) micrographs of the examined specimens after implantation process: (a) uncoated Ti specimen; (b) anodized coated Ti specimen.

surgical site. No adverse reaction was observed during the procedure. After implant insertion, slight initial limping was noticed in some animals, but no pronounced motion disorders were seen; neither were there signs of infection, failure to thrive, or other complications. The structure of bone surrounding the titanium implants appeared normal after $8 \mathrm{wk}$ of intramedullary osseointegration. There were obvious signs of bone remodeling adjacent to the proximal implant plate including changes in the size and shape of the bone and osteoclast activity resulting in new bone lamellae.

\subsection{Histological Findings}

Histological analysis of the cross sections from all tibiae confirmed the presence of bone ingrowth after 4 and 8 weeks of implantation of Ti-plate (Figure 7). The most proximal section, where there was incomplete filling of the tibia or where there had been inaccurate sizing during operative preparation of the canal, often had regions of fibrous-tissue encapsulation. Superficially, it was possible to observe a thin fibrous capsule covering the bone graft. Adjacent to the fibrous capsule it was possible to notice the bone graft with its osteocyte lacunae containing basophilic nucleus. Several bone lacunae were found into the grafts containing multinucleate cells. Deeply and adjacent to the bone surface of the recipient site, there were several resorption areas with a large number of osteoclastic-type multinucleate cells (Figures $\mathbf{7 ( b )}$ and (c)). It was still possible to observe the absence of a bone union between the bone graft and the recipient site Figures 8(a) and (b) show the cortical osteotomy site of bone after two months implantation of $\mathrm{TiO}_{2} / \mathrm{Ti}$-plate. Few fibroblasts could be identified, with a predominance of resorption areas concerning new bone formation areas. Discrete areas of new bone formation could be seen in the recipient site. Figure 9 shows the evascularization at 

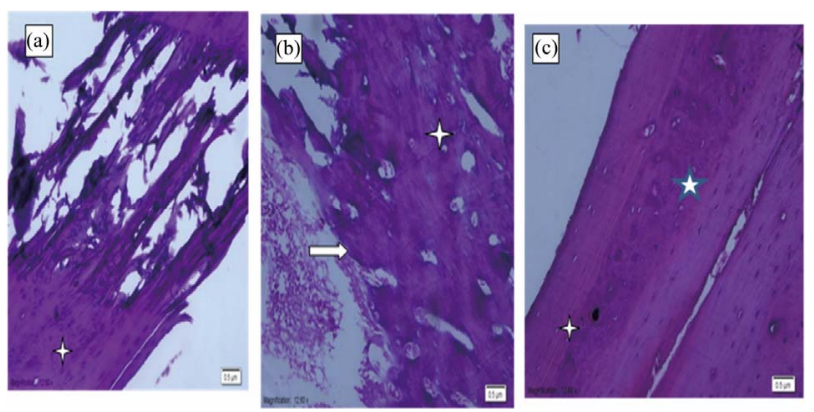

Figure 7. Photomicrographs of H\&E stained histological sections from bone after implantation of Ti-plate; (a) and (b) after 0 and 4 wk of implantation, respectively, where the peripheral region of graft; (c) after 8 wk of implantation bone (white arrow); bone-implant interface where new bone formation with primary bone tissue (asterisks) and original magnification $(\times 20)$.

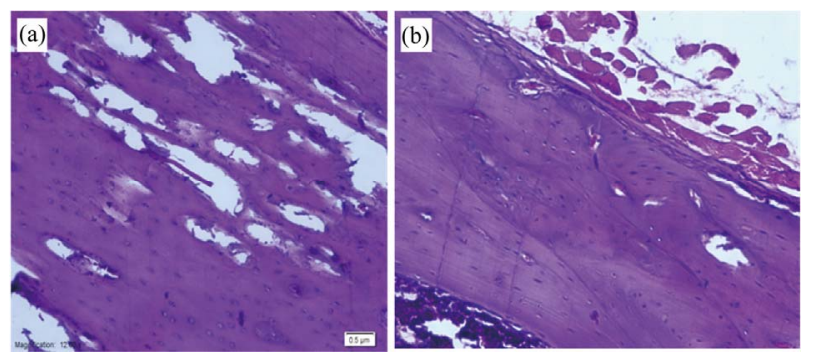

Figure 8. Photomicrographs of H\&E stained histological sections from bone after implantation of $\mathrm{TiO}_{2} / \mathrm{Ti}$ plate, (a) after 4 wk and (b) after 8 wk (×20).

the osteotomy site of bone two months after implantation of $\mathrm{TiO}_{2} / \mathrm{Ti}$-plate. Enlarging the haversian canals (HC), but several canals show no evidence of repair. The vast majority of the chondrocytes appear viable, with only small patches of a cellular matrix. There is no evidence of an inflammatory response. Figure $\mathbf{1 0}$ shows the reactive cartilage that is undergoing endochondral ossification; cartilage is growing (expanding) toward the left and cartilage with hypertrophying chondrocytes (Cc) and the condroblast (Cb).

\section{Discussion}

\subsection{New Bone Healing on $\mathrm{TiO}_{2} / \mathrm{Ti} /$ Bone Interface}

Osseointegration is fundamental process in orthopedic. Several literatures explained about the integration of the implant with adjacent bone and tissue [27-29]. Osseointegration defined as the process of formation of new bone and bone healing. The incapability of an implant surface was improved to join with the adjacent bone and other tissues through the formation of a fibrous tissue around the implant and promote loosening of the prostheses. Thus, materials with a proper surface are extremely essential for the implant to integrate well with the sur-

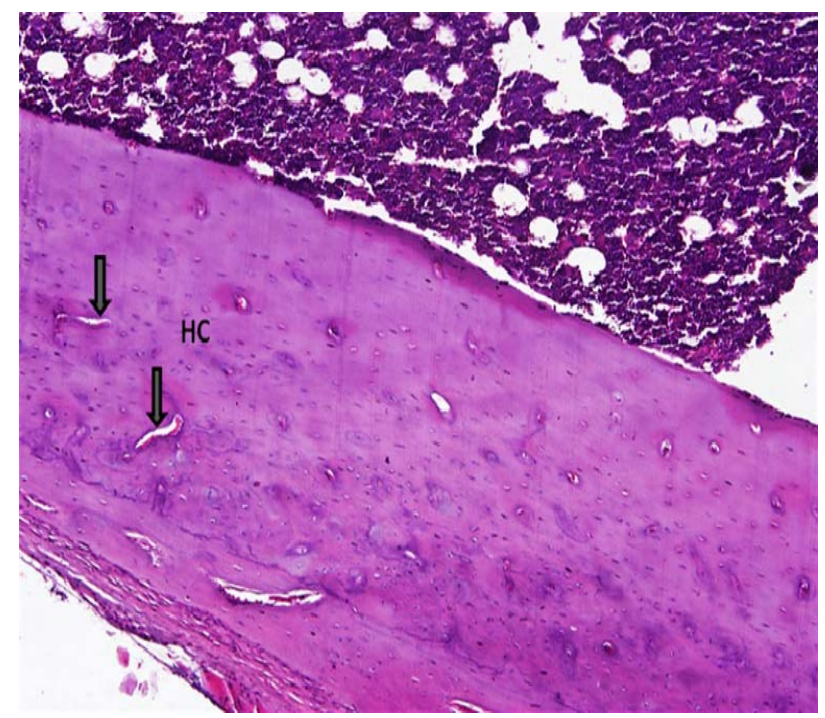

Figure 9. Revascularization at the osteotomy site. A photomicrograph showing the cortical osteotomy site of bone two months after implantation of $\mathrm{TiO}_{2} / \mathrm{Ti}$-plate (hematoxylin and eosin, $\times 10$ ). Enlarging the haversian canals (HC), but several canals show no evidence of repair. The vast majority of the chondrocytes appear viable, with only small patches of a cellular matrix. There is no evidence of an inflammatory response.

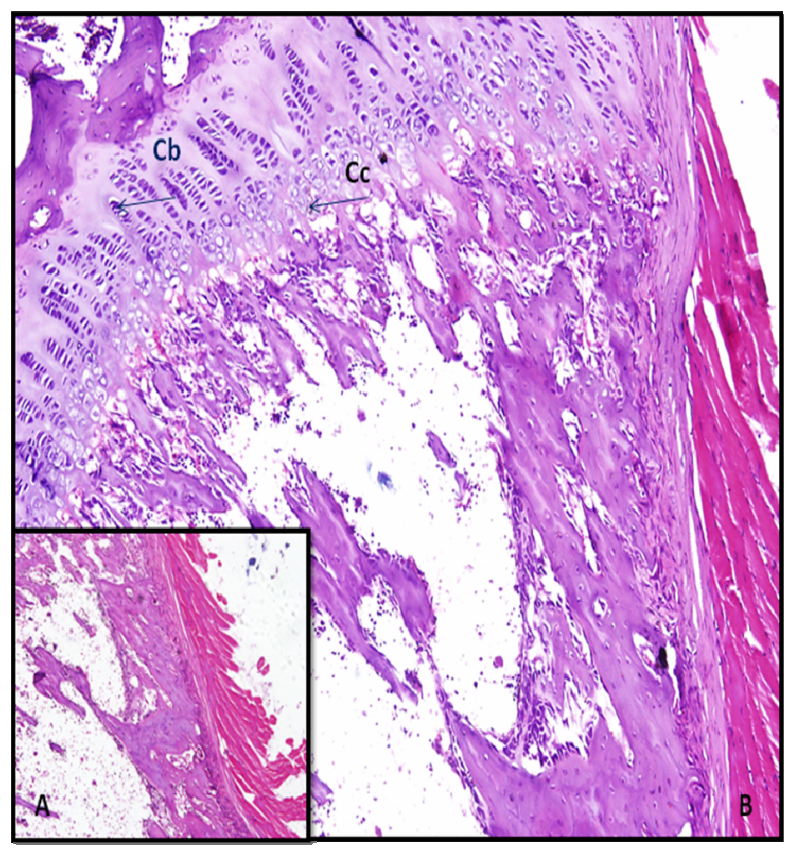

Figure 10. Photomicrographs shows reactive cartilage that is undergoing endochondral ossification after implantation of $\mathrm{TiO}_{2} / \mathrm{Ti}$ plate for 2 months; cartilage is growing (expanding) toward the left and cartilage with hypertrophying chondrocytes (Cc) (at right) however, the condroblast (Cb) at left $(A, \times 10$ and $B, \times 40)$.

rounding bone. Surface chemistry, roughness and topography are all parameters that influence both the osseoin- 
tegration and biocompatibility [30]. So, good biocompatibility and rapid osseointegration are essential factors of prolonged stability of the implant material.

Since Ti and its alloys has won as a good metallic biomaterial, researchers were keen to further improve the osseointegration of Ti by applied different surface modification method by altering the nature of the surface [3033]. Recently, $\mathrm{TiO}_{2}$ has been suggested as a bioactive surface to improve the osseointegration process. The advantage of using $\mathrm{TiO}_{2}$ is that it can be grown directly on the Ti surface, by cost-effective techniques such as anodic oxidation [34-36]. Also, it is well known that one problem with bone healing is poor adhesion strength at the Ti/bone interface [37-40]. By using anodic oxidation, $\mathrm{TiO}_{2}$ is formed with a chemical bond between the oxide and Ti substrate that likely results in enhanced adhesion strength of the bone.

Porous $\mathrm{TiO}_{2}$ films with controlled nanostructures were prepared reproducibly and conveniently by potentiostatic anodic oxidation in different electrolyte [41-43]. Our previous research has shown that it is possible to increase the range of titanium in medical application by depositing a porous layer of $\mathrm{TiO}_{2}$ on the metal surface [44-46]. The objectives of the present work are to assess the effect of $\mathrm{TiO}_{2}$ coat prepared $1 \mathrm{M} \mathrm{H}_{2} \mathrm{SO}_{4}+0.5 \mathrm{wt} \% \mathrm{NaF}$ to obtain a new anodized titania to evaluate histological effect of $\mathrm{Ti} /$ bone and $\mathrm{TiO}_{2} / \mathrm{Ti} /$ bone interfaces and to contribute clinically relevant data on the permanence of titanium metal structures used in osteosynthesis in the body.

The oxide film formed in $1 \mathrm{M} \mathrm{H}_{2} \mathrm{SO}_{4}$ and $0.5 \mathrm{wt} \%$ $\mathrm{NaF}$ has higher nano porous structure compared with our previous work that formed in $0.5 \mathrm{M} \mathrm{H}_{2} \mathrm{SO}_{4}$, and that formed in 1.4 $\mathrm{M} \mathrm{H}_{3} \mathrm{PO}_{4}$ [44], Figure 1(b) predicated that a good healing are occurring on nano- $\mathrm{TiO}_{2} / \mathrm{Ti} /$ bone interface surface.

By comparing the tibiae of implanted uncoated Ti with that of coated anodized $\mathrm{Ti}$, note that there is a different in the size of two implanted tibiae. The coated implanted tibiae are larger than the uncoated implanted tibiae (Figures 3(a) and (b)). This result is considered as a good observation and may be attributed to the excellent bone healing process on $\mathrm{TiO}_{2} / \mathrm{Ti} /$ bone interface and perhaps draws the authors to further future study. The detection of both implanted tibiae by X-ray investigation indicated that the high bone regeneration on coated implanted tibiae need more time to get a normal bone shape without any apparent defect (Figure 4(c)).

Electrochemical formation and characterization of porous titanium $\left(\mathrm{TiO}_{2}\right)$ films [46], which eventually causes the adhesion of bone cells, albeit at a much slower quantity than the $\mathrm{TiO}_{2}$ nano porous surface investigated in this work (Figure 5). The bone cells show a spreading morphology and network formation on the coated anodized Ti surface. This result confirmed that the nano-scaled bioactive $\mathrm{TiO}_{2}$ nanostructures incorporated in this investigation form strongly bonded and stable nano-porous layer, which can increase the bone cells on its surface and reduce the interfacial fracture [47]. A close look at the areas surrounding the cells confirms that the nano pores are being filled in with bone matrix. These results are fully compatible with the findings of researchers [48]. The surface properties of biomaterials play a critical role in the establishment of cell-biomaterial interfaces [49].

\subsection{Histological Evaluation of Ti Implant Samples}

Microscopic observation of the implant/bone interface at this time-point indicated successful osseointegration with normal remodeled bone adjacent to the fixture [20]. The presence of corrosion products has been found in blood analysis [50]. In some cases the products of corrosion were found around the blood vessels, in keeping with the findings of Meachim and Williams [51] and Torgersen et al. [52], in a histological study of soft tissue adjacent to titanium implants. The observation of metal particles located intracellular or in association with vessels may represent a biological response aimed at eliminating the foreign material [52,53]. The properties and quality of the implant material, the shape of the implant and the handling and surgical procedure are of crucial importance for an optimal biological performance of any implant device [1]. Titanium dioxide is generally considered to be of low toxicity $[1,50]$.

Brånemark has studied the processes of osseointegration for endosseous titanium implants in long bones under various conditions [53]. The present results indicated that histological analysis of all fixtures showed a direct bone contact with the titanium surface at the resolution level of the light microscope as described before [53]. In our study, plate implants with coated porous surface $\left(\mathrm{TiO}_{2} / \mathrm{Ti}\right)$ were compared to plate implants with uncoated surface regarding the new bone formation on the implant-bone interface after implantation in rat tibiae. The results showed no difference of new bone quality between both types of implants. However, when the quantity of bone new formation at implant-bone interface was evaluated, a larger formation of bone tissue was observed for the $\mathrm{TiO}_{2} /$ Ti-surface implants. The most important factors to implant osseointegration are related to the characteristics of its surfaces, which include topography and chemical and electric properties of the material [54], since boneimplant interaction is mainly related to the most external layers of the implants [55]. Important factors to a more successful osseointegration are: implant material, implant shape, surgical technique [15], quantity of bone tissue [15], load [56] and implant resistance [4]. However, some other factors such as surface energy, sterilization techniques and chemical and topographic properties of 
the implant surface are extremely important for the final outcome of osseointegration [15,50,57].

Bone growth is also dependent on factors such as percentage of surface porosity and the presence of gaps between the implant and the bone at the time of placement [15]. Therefore, in order to obtain osseointegration, the surgical cavity must be prepared with the least injury possible $[15,50,58]$. In order to cause minimal damage to the surrounding bone tissues, in the present study, bone perforation was performed using burs of increasingly larger diameters, and under constant saline irrigation. After that, the implants were gently pressed into the surgical cavity, which diminished the gap between the implant and the bone and promoted efficient stability.

Some previous studies used a 4-week healing period to evaluate the biocompatibility of metal materials $[15,59]$. Healing periods were longer than 4 weeks added no benefits to increase the quantity of bone tissue ingrowth into porous-surface implants, and observed that only bone tissue maturation took place after this period [15]. Thus, in the present study, an 8-week period was used to evaluate the biocompatibility of $\mathrm{TiO}_{2} / \mathrm{Ti}$-surface grade as compared to commercially pure Ti-implants fabricated by means of anodic oxidation technique. The purpose of studying and developing $\mathrm{TiO}_{2} / \mathrm{Ti}$-surface implants is to promote a more stable and biocompatible fixation of titanium implants. The creation of a $\mathrm{TiO}_{2}$ surface aims not only at increasing contact area but also at allowing bone ingrowth into the pores, including those located more centrally. Such ingrowth is due to pore intercommunication, which produces a three-dimensional net and allows a mechanical entanglement [15,60]. More bone formation was significantly observed in the $\mathrm{TiO}_{2}$-surface implants. The results of this study showed that because of the larger contact surface promoted by the presence of pores, there was more bone ingrowth on the implant-bone interface. Such results are consistent with those of Deporter et al. [60], Karabuda et al. [58] and Zinger et al. [61] who also observed more effectiveness of the porous-surface implants compared to other types of implants.

Our results show improvement in cell attachment and spreading on $\mathrm{TiO}_{2} / \mathrm{Ti}$ coated as compared to uncoated $\mathrm{Ti}$, which is in line with previous studies [6,62]. During the initial period of bone healing, the mesenchymal cells move into the inflamated site and differentiate into osteoblasts, which allow the osteoid formation. The presence of mesenchymal cells in abundance at the healing zone between the $\mathrm{TiO}_{2}$-coated implant and the mature bone indicates the commencement of bone regeneration [6]. In our study, formation of osteoid on the $\mathrm{TiO}_{2} / \mathrm{Ti}$ coated implant surface confirms the cellular activity required for the new bone formation. These results are in accordance with earlier studies which show faster new bone formation on hydroxy apatite coated implants $[6,63]$.
The skeleton is a metabolically active organ that undergoes continuous remodeling throughout life. Bone remodeling involves the removal of mineralized bone by osteoclasts followed by the formation of bone matrix through the osteoblasts that subsequently become mineralized [64]. The remodeling cycle consists of three consecutive phases: resorption, during which osteoclasts digest old bone; reversal, when mononuclear cells appear on the bone surface; and formation, when osteoblasts lay down new bone until the resorbed bone is completely replaced. Bone remodeling serves to adjust bone architecture to meet changing mechanical needs and it helps to repair microdamages in bone matrix preventing the accumulation of old bone. It also plays an important role in maintaining plasma calcium homeostasis [65].

\section{Conclusion}

According to the methodology employed in this study, it was possible to conclude that, the anodic oxidation technique improved the surface of titanium by forming a film of nano-porous oxide layer. This porous-surface improved the osseointegration process because it encourages the bone healing at $\mathrm{TiO}_{2} / \mathrm{Ti} /$ bone interface. Therefore, the results showed that the roughness $\mathrm{TiO}_{2} / \mathrm{Ti}$ implant surface is better than the smooth Ti surface and well tolerated when placed in rat tibiae, thus corroborating the findings of previous studies that indicated modified titanium plate as the best biomaterial for bone surgical implants.

\section{Acknowledgements}

This research was supported by funding source from Center of Research Excellence in Corrosion, King Fahd University of Petroleum and Minerals, Al-Read, KSA. This study was parts of the Grant No. CR-12-2010.

\section{REFERENCES}

[1] D. G. Olmedo, G. Duffó, R. L. Cabrini and M. B. Guglielmotti, "Local Effect of Titanium Implant Corrosion: An Experimental Study in Rats," International Journal of Oral and Maxillofacial Surgery, Vol. 37, No. 11, 2008, pp. 1032-1038. doi:10.1016/j.ijom.2008.05.013

[2] R. M. Wazen, L.-P. Lefebvre, E. Baril and A. Nanci, “Initial Evaluation of Bone Ingrowth into a Novel Porous Titanium Coating," Journal of Biomedical Materials Research Part B: Applied Biomaterials, Vol. 94B, No. 1, 2010, pp. 64-71.

[3] S. Abramson, H. Alexander, S. Best, J. C. Bokros, J. B. Brunski, A. Colas, S. L. Cooper, J. Curtis, A. Haubold, L. L. Hench, R. W. Hergenrother, A. S. Hoffman, J. A. Hubbell, J. A. Jansen, M. W. King, J. Kohn, M. K. Lamba, R. Langer, C. Migliaresi, R. B. More, N. A. Peppas, B. D. Ratner, S. A. Visser, A. von Recum, S. Weinberg and I. V. Yannas, "Classes of Materials Used in Medicine," In: B. 
Ratner, A. Hoffman, F. Schoen and J. Lemons, Eds., Biomaterials Science, Elsevier Academic Press, San Diego, 2004, pp. 67-233.

[4] R. Adell, B. Ericksson, V. Lekholm, P. I. Bränemark and T. Jemt, “A Long-Term Follow Up Study of Osseointegrated Implants in the Treatment of the Totally Edentulous Jaw," International Journal of Oral and Maxillofacial Surgery, Vol. 5, No. 4, 1990, pp. 347-359.

[5] T. Albrektsson, "A Multicenter Report on Osseointegrated Oral Implants,” Journal of Prosthetic Dentistry, Vol. 60 , No. 1,1988 , pp. 75-84. doi:10.1016/0022-3913(88)90355-1

[6] M. Roy, A. Bandyopadhyay and S. Bose, "Induction Plasma Sprayed Nano Hydroxyapatite Coatings on Titanium for Orthopaedic and Dental Implants," Surface and Coatings Technology, Vol. 205, No. 8-9, 2011, pp. 27852792.

[7] T. Koklubo, H. M. Kim and M. Kawashita, "Novel Bioactive Materials with Different Mechanical Properties," Biomaterials, Vol. 24, No. 13, 2003, pp. 2161-2175. doi:10.1016/S0142-9612(03)00044-9

[8] R. K. Shenk and D. Buser, “Osseointegration: A Reality," Periodontology 2000, Vol. 17, No. 1, 1998, pp. 22-35. doi:10.1111/j.1600-0757.1998.tb00120.x

[9] B. J. Brunski, "In Vivo Bone Response to Biomechanical Loading at the Bone/Dental-Implant Interface,” Advances in Dental Research, Vol. 13, No. 1, 1999, pp. 99-119. doi:10.1177/08959374990130012301

[10] A. Bagno and C. D. Bello, "Surface Treatments and Roughness Properties of Ti-Based Biomaterials,” The Journal of Materials Science: Materials in Medicine, Vol. 15, No. 9, 2004, pp. 935-949. doi:10.1023/B:JMSM.0000042679.28493.7f

[11] P. I. Branemark, "Osseointegration and Its Experimental Background,” Journal of Prosthetic Dentistry, Vol. 50, No. 3, 1983, pp. 399-410. doi:10.1016/S0022-3913(83)80101-2

[12] R. M. Pilliar, "Overview of Surface Variability of Metallic Endosseous Dental Implants: Textured and Porous Surface-Structured Designs,” Implant Dentistry, Vol. 7, No. 4, 1998, pp. 305-314. doi:10.1097/00008505-199807040-00009

[13] O. Zinger, G. Zhao, Z. Schwartz, J. Simpson, M. Wieland, D. Landolt, et al., "Differential Regulation of Osteoblasts by Substrate Microstructural Features,” Biomaterials, Vol. 26, No. 14, 2005, pp. 1837-1847. doi:10.1016/j.biomaterials.2004.06.035

[14] A. S. Brentel, L. M. R. de Vasconcellos, M. V. Oliveira, A. M. L. Graça, L. G. O. de Vasconcellos, C. A. A. Cairo and Y. R. Carvalho, "Histomorphometric Analysis of Pure Titanium Implants with Porous Surface versus Rough Surface,” Journal of Applied Oral Science, Vol. 14, No. 3, 2006, pp. 213-218. doi:10.1590/S1678-77572006000300013

[15] J. E. Ellingsen, "Surface Configurations of Dental Implants,” Periodontology 2000, Vol. 17, No. 1, 1998, pp. 36-46.

[16] B. Kasemo, "Biocompatibility of Titanium Implants: Sur- face Science Aspects,” Journal of Prosthetic Dentistry, Vol. 49, No. 6, 1983, pp. 832-837. doi:10.1016/0022-3913(83)90359-1

[17] J. Svehla, P. Morberg, B. Zicat, W. Bruce, D. Sonnabend and W. R. Walsh, "Morphometric and Mechanical Evaluation of Titanium Implant Integration: Comparison of Five Surface Structures,” Biomedical Material Research, Vol. 51, No. 1, 2000, pp. 15-22. doi:10.1002/(SICI)1097-4636(200007)51:1<15::AID-JB M3>3.0.CO;2-9

[18] M. V. Oliveira, L. C. Pereira and C. A. A. Cairo, "Porous Structure Characterization in Titanium Coating for Surgical Implants,” Material Research, Vol. 5, No. 3, 2002, pp. 269-273. doi:10.1590/S1516-14392002000300009

[19] M. Ysander, R. Brånemark, K. Olmarker and R. R. Myers, "Intramedullary Osseointegration: Development of a Rodent Model and Study of Histology and Neuropeptide Changes around Titanium Implants,” The Journal of Rehabilitation Research and Development, Vol. 38, No. 2, 2001, pp. 183-190.

[20] H. Q. Nguyen, D. A. Deporter, R. M. Pilliar, N. Valiquette and R. Yakubovich, "The Effect of Sol-Gel Formed Calcium Phosphate Coatings on Bone Ingrowth and Osteoconductivity of Porous-Surfaced Ti Alloy Implants," Biomaterial, Vol. 25, No. 5, 2004, pp. 865-876. doi:10.1016/S0142-9612(03)00607-0

[21] F. Togni, F. Baras, M. de O. Ribas and M. O. Taha, "Histomorphometric Analysis of Bone Tissue Repair in Rabbits after Insertion of Titanium Screws under Different Torque,” Acta Cirurgica Brasileira, São Paulo, Vol. 26, No. 4, 2011, pp. 235-241.

[22] M. Quahtany, S. A. Fadl-allah and N. S. El-Shenawy, "Microstructures and Electrochemical Behavior of Biomimetic Calcium-Phosphate Coating in Albumin Simulated Body Fluids," International Journal of Electrochemical Science, Vol. 7, 2012, pp. 4510-4527.

[23] R. L. Cabrini, M. B. Guglielmotti and J. C. Almagro, "Histomorphometry of Initial Bone Healing around Zirconium Implants in Rats,” Implant Dentistry, Vol. 2, No. 4, 1993, pp. 264-267. doi:10.1097/00008505-199312000-00008

[24] C. Y. Yang, T. M. Lee, C. W. Yang, L. R. Chen, M. C. $\mathrm{Wu}$ and T. S. Lu, "The in Vitro and in Vivo Biological Responses of Plasma-Sprayed Hydroxyapatite Coatings with Post-Hydrothermal Treatment," Journal of Biomedical Material Research, Vol. 83A, No. 2, 2007, pp. 263271. doi:10.1002/jbm.a.31246

[25] H. E. Gruber, “Adaptations of Goldner’s Masson Trichrome Stain for the Study of Undecalcified Plastic Embedded Bone,” Biotechnic and Histochemistry, Vol. 67, No. 1, 1992, pp. 30-34. doi:10.3109/10520299209110002

[26] J. Alvarado, et al., "Biomechanics of Hip and Knee Prostheses," Applications of Engineering Mechanics in Medicine, GED, University of Puerto Rico Mayaguez, 2003.

[27] M. Geetha, et al., "Ti Based Biomaterials, the Ultimate Choice for Orthopaedic Implants-A Review,” Progress in Materials Science, Vol. 54, No. 3, 2009, pp. 397-425.

[28] M. Long and H. J. Rack, “Titanium Alloys in Total Joint Replacement-A Materials Science Perspective,” Bioma- 
terials, Vol. 19, No. 18, 1998, pp. 1621-1639. doi:10.1016/S0142-9612(97)00146-4

[29] N. Mirhosseini, et al., "Laser Surface Micro-Texturing of Ti-6Al-4V Substrates for Improved Cell Integration,” Applied Surface Science. Vol. 253, No. 19, 2007, pp. 77387743. doi:10.1016/j.apsusc.2007.02.168

[30] A. Shenhar, et al., "Surface Modification of Titanium Alloy Orthopaedic Implants via Novel Powder Immersion Reaction Assisted Coating Nitriding Method,” Materials Science \& Engineering A, Structural Materials: Properties Microstructure and Processing, Vol. 268, No. 1-2, 1999, pp. 40-46.

[31] P. Budzynski, A. A. Youssef and J. Sielanko, "Surface Modification of Ti-6Al-4V Alloy by Nitrogen Ion Implantation,” Wear, Vol. 261, No. 11-12, 2006, pp. 12711276. doi:10.1016/j.wear.2006.03.008

[32] B. H. Lee, et al., "Effect of Surface Structure on Biomechanical Properties and Osseointegration," Materials Science \& Engineering, Vol. 28, No. 8, 2008, pp. 14481461.

[33] H. M. Kim, H. Kaneko, M. Kawashita, T. Kokubo and T. Nakamura, "Mechanism of Apatite Formation on Anodically Oxidized Titanium Metal in Simulated Body Fluid," Key Engineering Materials, Vol. 254-256, 2004, pp. 741744. doi:10.4028/www.scientific.net/KEM.254-256.741

[34] H. M. Kim, T. Himeno, M. Kawashita, J. H. Lee, T. Kokubo and T. Nakamura, "Surface Potential Change in Bioactive Titanium Metal during the Process of Apatite Formation in Simulated Body Fluid," Journal of Biomedical Materials Research, Vol. 67A, No. 4, 2003, pp. 1305-1309. doi:10.1002/jbm.a.20039

[35] B. Yang, M. Uchida, H. M. Kim, X. Zhang and T. Kokubo, "Preparation of Bioactive Titanium Metal via Anodic Oxidation Treatment,” Biomaterials, Vol. 25, No. 6, 2004, pp. 1003-1010. doi:10.1016/S0142-9612(03)00626-4

[36] K. Degroot, R. Geesink, C. P. A. T. Klein and P. Serekian, "Plasma Sprayed Coatings of Hydroxyapatite," Journal of Biomedical Materials Research, Vol. 21, No. 12, 1987, pp. 1375-1381. doi:10.1002/jbm.820211203

[37] R. Mcpherson, N. Gane and T. J. Bastow, "Structural Characterization of Plasma-Sprayed Hydroxylapatite Coatings," Journal of Materials Science Materials in Medicine, Vol. 6, No. 6, 1995, pp. 327-334.

[38] H. Kurzweg, R. B. Heimann and T. Troczynski, “Adhesion of Thermally Sprayed Hydroxyapatite-Bond-Coat Systems Measured by a Novel Peel Test," Journal of Materials Science Materials in Medicine, Vol. 9, No. 1, 1998, pp. 9-16.

[39] C. M. Lin and S. K. Yen, "Characterization and Bond Strength of Electrolytic $\mathrm{HA} / \mathrm{TiO}_{2}$ Double Layers for Orthopedic Applications," Journal of Materials Science Materials in Medicine, Vol. 16, No. 10, 2005, pp. 889897.

[40] W. Chen, Y. Liu, H. S. Courtney, M. Bettenga, C. M. Agrawal, J. D. Bumgardner and J. L. Ong, "In Vitro AntiBacterial and Biological Properties of Magnetron CoSputtered Silver-Containing Hydroxyapatite Coating," Biomaterials, Vol., 27, No. 32, 2006, pp. 5512-5517. doi:10.1016/j.biomaterials.2006.07.003

[41] Z. Huan, L. E. Fratila-Apachitei, I. Apachitei and J. Duszczyk, "Porous NiTi Surfaces for Biomedical Applications,” Applied Surface Science, Vol. 258, No. 13, 2012, pp. 5244-5249. doi:10.1016/j.apsusc.2012.02.002

[42] C. Y. Chiang, S. H. Chiou, W. E. Yang, M. L. Hsu, M. C. Yung, M. L. Tsai, L. K. Chen and H. H. Huang, "Formation of $\mathrm{TiO}_{2}$ Nano-Network on Titanium Surface Increases the Human Cell Growth,” Dental Materials, Vol. 25, No. 8, 2009, pp. 1022-1029. doi:10.1016/j.dental.2009.03.001

[43] S. A. Fadl-allah and Q. Mohsen, "Characterization of Native and Anodic Oxide Films Formed on Commercial Pure Titanium Using Electrochemical Properties and Morphology Techniques,” Applied Surface Science, Vol. 256, No. 20. 2010, pp. 5849-5855. doi:10.1016/j.apsusc.2010.03.058

[44] Q. Mohsen and S. A. Fadl-allah, "Improved in Corrosion Resistance of Commercial Pure Titanium for the Enhancement of Its Biocompatibility," Materials and Corrosion, Vol. 62, No. 4, 2011, pp. 310-319.

[45] S. A. Fadl-Allah, R. M. El-Sherief and W. A. Badawy, "Electrochemical Formation and Characterization of Porous Titania $\left(\mathrm{TiO}_{2}\right)$ Films on Ti," Journal of Applied Electrochemistry, Vol. 38, No. 10, 2008, pp. 1459-1466. doi:10.1007/s10800-008-9590-7

[46] O. H Seunghan and J. N. Sungho, “Titanium Oxide Nanotubes with Controlled Morphology for Enhanced Bone Growth,” Materials Science and Engineering, Vol. C26, 2006, 1301-1306.

[47] K. C. Popat, L. Leoni, C. A. Grimes and T. A. Desai, “Influence of Engineered Titania Nanotubular Surfaces on Bone Cells,” Biomaterials, Vol. 28, No. 21, 2007, pp. 3188-3197. doi:10.1016/j.biomaterials.2007.03.020

[48] K. Anselme, M. Bigerelle, B. Noel, E. Dufresne, D. Judas, A. Iost and P. Hardouin, "Qualitative and Quantitative Study of Human Osteoblast Adhesion on Materials with Various Surface Roughnesses," Journal of Biomedical Material Research, Vol. 49, No. 2, 2000, pp. 155-166. doi:10.1002/(SICI)1097-4636(200002)49:2<155::AID-JB M2>3.0.CO;2-J

[49] N. S. El-Shenawy, Q. Mohsen and S. A. Fadl-allah, "Oxidative Stress and Antioxidant Responses of Liver and Kidney Tissue after Implantation of Titanium or Titanium Oxide Coated Plate in Rat Tibiae," Journal of Material Science: Material Medical, Vol. 23, No. 7, 2012, pp. 1763-1774. doi:10.1007/s10856-012-4648-9

[50] G. Meachim and D. F. Williams, "Changes in Nonosseous Tissue Adjacent to Titanium Implants," Journal of Biomedical Material Research, Vol. 7, No. 6, 1973, pp. 555-572. doi:10.1002/jbm.820070607

[51] S. Torgersen, N. R. Gjedet, E. S. Erichsen and G. Bang, "Metal Particles and Tissue Changes Adjacent to Miniplates. A Retrieval Study,” Acta Odontologica Scandinavica, Vol. 53, No. 2, 1995, pp. 65-71. doi:10.3109/00016359509005948

[52] R. Brånemark, “A Biomechanical Study of Osseointegration. In-Vivo Measurements in Rat, Rabbit, Dog and Man,” Thesis ISBN91-628-226775, Gothenburg Univer- 
sity, Gothenburg, 1996.

[53] R. M. Pilliar, "Overview of Surface Variability of Metallic Endosseous Dental Implants: Textured and Porous Surface-Structured Designs," Implant Dentistry, Vol. 4, No. 4, 1998, pp. 305-314. doi:10.1097/00008505-199807040-00009

[54] M. Fini, L. Savarino, N. N. Aldini, L. Martini, G. Giavaresi, G. Rizzi, et al., "Biomechanical and Histomorphometric Investigations on Two Morphologically Differing Titanium Surfaces with and without Fluorhydroxyapatite Coating: An Experimental Study in Sheep Tibiae,” Biomaterials, Vol. 24, No. 19, 2003, pp. 3183-3192. doi:10.1016/S0142-9612(03)00164-9

[55] M. G. V. Junior, L. C. A. Aragones, A. C. Junior and M. Groisman, "Histomorphometric Analyses of Hydroxyapatite-Coated and Uncoated Titanium Dental Implants in Rabbit Cortical Bone,” Implant Dentistry, Vol. 8, No. 3, 1999, pp. 295-302. doi:10.1097/00008505-199903000-00015

[56] I. Braceras, J. I. Alava, J. I. Oñate, M. Brizela, A. GarciaLuis, N. Garagorri, et al., "Improved Osseointegration in Ion Implantation-Treated Dental Implants,” Surface Coating Technology, Vol. 158-159, 2002, pp. 28-32.

[57] C. Karabuda, P. Sandalli, S. Yalcin, D. E. Steflik and G. R. Parr, "Histologic and Histomorphometric Comparison of Immediately Placed Hydroxyapatite-Coated and Titanium Plasma-Sprayed Implants: A Pilot Study in Dogs,” International Journal of Oral and Maxillofacial Implants, Vol. 14, No. 4, 1999, pp. 510-515.

[58] K. H. Frosch, F. Barvencik, C. H. Lohmann, V. Viereck, H. Siggelkow, J. Breme, et al., "Migration, Matrix Production and Lamellar Bone Formation of Human Osteoblast-Like Cells in Porous Titanium Implants,” Cells Tissues Organs, Vol. 170, No. 4, 2002, pp. 214-227. doi:10.1159/000047925
[59] D. A. Deporter and R. N. Todescan, "Riley Porous-SurFaced Dental Implants in the Partially Edentulous Maxilla: Assessment for Subclinical Mobility,” International Journal of Periodontics and Restorative Dentistry, Vol. 22, No. 2, 2002, pp. 184-192.

[60] O. Zinger, G. Zhao, Z. Schwartz, J. Simpson, M. Wieland, D. Landolt, et al., "Differential Regulation of Osteoblasts by Substrate Microstructural Features," Biomaterial, Vol. 26, No. 14, 2005, pp. 1837-1847. doi:10.1016/j.biomaterials.2004.06.035

[61] G. S. Kumar, A. Thamizhave, Y. Yokogawa, S. N. Kalkura and E. K. Girija, "Synthesis, Characterization and in Vitro Studies of Zinc and Carbonate Co-Substituted NanoHydroxyapatite for Biomedical Applications," Materials Chemistry and Physics, Vol. 134, No. 2-3, 2012, pp. 1127-1135. doi:10.1016/j.matchemphys.2012.04.005

[62] X. Liu, P. K. Chu and C. Ding, "Surface Modification of Titanium, Titanium Alloys, and Related Materials for Biomedical Applications,” Material Science Engineering, Vol. 47, No. 3-4, 2004, pp. 49-121. doi:10.1016/j.mser.2004.11.001

[63] N. Hansen-Algenstaedt, C. Joscheck, L. Wolfram, C. Schaefer, I. Müller, A. Böttcher, G. Deuretzbacher, L. Wiesner, M. Leunig, P. Algenstaedt and W. Rüther, "Sequential Changes in Vessel Formation and Micro-Vascular Function during Bone Repair," Acta Orthopaedica, Vol. 77, No. 3, 2006, pp. 429-439. doi:10.1080/17453670610046361

[64] J. C. Esteves, A. G. Borrasca, A. M. Aranega, I. R. G. Junior and O. M. Filho, "Histomorphometric Analysis of the Repair Process of Autogenous Bone Grafts Fixed at Rat Calvaria with Cyanoacrylate," Journal of Applied Oral Science, Vol. 19, No. 5, 2011. doi:10.1590/S1678-77572011000500016 